\title{
Effect of case-based learning in reproductive physiology on cognitive domain scores of first-year medical students in Western India
}

\author{
Srabani N. Bhattacharya1, Aniruddha A. Malgaonkar ${ }^{2 *}$, Sundaram Kartikeyan²
}

\begin{abstract}
${ }^{1}$ Department of Physiology, ${ }^{2}$ Department of Community Medicine, Rajiv Gandhi Medical College, Kalwa, Thane, Maharashtra, India
\end{abstract}

Received: 05 April 2017

Accepted: 02 May 2017

\section{*Correspondence: \\ Dr. Aniruddha A. Malgaonkar, \\ E-mail: andydr@rediffmail.com}

Copyright: (c) the author(s), publisher and licensee Medip Academy. This is an open-access article distributed under the terms of the Creative Commons Attribution Non-Commercial License, which permits unrestricted non-commercial use, distribution, and reproduction in any medium, provided the original work is properly cited.

\begin{abstract}
Background: The Medical Council of India has recommended early clinical exposure, problem-oriented approach and case-based learning throughout the graduate medical curriculum. Case-based learning is a teaching-learning model that helps effective use of student and faculty time.

Methods: This complete-enumeration, before-and-after type of educational intervention study (without controls) was conducted in a municipal medical college in Western India. After explaining the objectives of the study to first-year medical students, aged 18 years and above, of either sex, written informed consent was obtained from students $(\mathrm{n}=55$ ) who were willing to participate in the study. The pre-test was conducted after lectures by faculty from the Departments of Physiology and Community Medicine. An identical post-test was administered after case-based learning, which was conducted by the same faculty in two sub-groups. The outcome studied was the difference in cognitive domain scores after attending lectures (by a pre-test) and case-based learning (by a post-test).

Results: The overall mean score increased from $5.36 \pm 0.97$ (95\% CI: $5.11-5.62)$ in the pre-test to $6.49 \pm 1.14(95 \%$ CI: 6.19 - 6.79) in the post-test. The differences between the pre- and post-test correct responses were statistically significant for two questions.

Conclusions: The participating first-year medical students had adequate basic knowledge of reproductive physiology. Gender differences in correct responses were statistically significant for few questions. Use of case scenarios enhanced cognitive domain scores.
\end{abstract}

Keywords: Case-based learning, Reproductive physiology

\section{INTRODUCTION}

The Medical Council of India has specified that the learning process for graduate medical education should include problem-oriented approach and case studies and that both horizontal and vertical integration are to be introduced throughout the curriculum. ${ }^{1}$

Case-based learning (CBL) is a discussion-based smallgroup learning method that makes use of a guided inquiry method. CBL enhances comprehension and acquisition of cognitive skills since learning is placed within its milieu. Learning and its retention is enabled when the topic is connected to real-life situations since the students realise the necessity of understanding the topic for future clinical practice. $^{2}$

The curriculum for the Bachelor of Medicine and Bachelor of Surgery (MBBS) course is considerable and students are expected to learn many subjects simultaneously. Besides, the faculty is engaged in many 
non-teaching activities, such as, administration and research. Therefore, the sheer vastness of the MBBS curriculum calls for effective usage of both student and faculty time and herein the CBL format offers another teaching-learning model.

CBL enhances reasoning skills and grasp of a basic science subject, such as physiology, since learning is placed within the framework of a practical problem. ${ }^{3}$ CBL has been compared with the traditional lecture format. ${ }^{4-8}$ Traditional lectures are reportedly more helpful to students in preparing for a written examination though these have been denigrated for generating information overload with deficient critical thinking. ${ }^{9,10}$

Case scenarios have been utilized to enable learning. ${ }^{2,11-13}$ CBL makes use of actual or hypothetical case scenarios as springboards to generate interest in a specific topic. ${ }^{2}$ If the case scenarios span across multiple topics, the students create inter-concept linkages that boost retention of knowledge and the students tend to develop a holistic perspective. $^{12,14}$

In CBL, the faculty formulate the case scenarios and students discuss the case in small groups and attempt to arrive at a solution using the knowledge gained from previously taught curricular content. CBL has been shown to impart early clinical exposure, assist students to link clinical conditions to basic sciences and develop clinical reasoning, improve student's scores, enhance communication skills, and galvanise the students towards self-directed learning. ${ }^{13}$

The objectives of the present study were to assess the cognitive domain scores of the participating first-year MBBS students after attending lectures on reproductive physiology (using a pre-CBL test) and to compare these with the cognitive domain scores after using CBL as the educational intervention (using an identical post-CBL test).

\section{METHODS}

This complete-enumeration, before-and-after type of educational intervention study (without controls) was conducted in 2016 in a municipal medical college in Kalwa, Thane, located about 30 kilometres from Mumbai city in the state of Maharashtra in Western India.

After obtaining permissions from the Institutional Ethics Committee (IEC) and institutional authorities, the objective of the study was explained to first year medical students, aged 18 years and above, of either sex, who were enrolled for the Bachelor of Medicine, Bachelor of Surgery (MBBS) course.

Written informed consent was obtained from students $(n=55)$ who were willing to participate in the study.
Lectures on reproductive physiology and its applied aspects, including contraception were delivered by faculty from the Departments of Physiology and Community Medicine. The pre-test, conducted after the lectures, comprised nine questions (one mark per question). The total marks obtainable were nine. For CBL, the participating students were randomly assigned (using lottery system) to two sub-groups comprising 28 and 27 students to enable small-group discussion. Each sub-group was identically exposed to case-based learning modules using case scenarios pertaining to applied aspects of reproductive physiology, including contraception. The same faculty jointly guided the discussion and encouraged participation of all students in each sub-group. The post-test was conducted after CBL, using a questionnaire that was identical to that of the pretest. The scores from students in the two sub-groups were amalgamated for analysing results of the pre- and posttests. The outcome studied was the difference in cognitive domain scores after attending lectures (by a pre-test) and CBL (by a post-test).

The data were tabulated and statistically analysed using EpiInfo Version 7.0 (public domain software package from the Centers for Disease Control and Prevention, Atlanta, GA, USA). Continuous data were presented as Mean and Standard Deviation (SD). Confidence interval (CI) was stated in the range of [Mean-(1.96)* Standard Error)] to [Mean+(1.96)* Standard Error)]. Significance of difference in parameters was determined using Karl Pearson's Chi-square test (with Mantel-Haenszel correction, where required) at $\mathrm{p}<0.05$. The standard error of difference between two means was calculated and statistical significance was determined at $\mathrm{p}<0.05$.

\section{RESULTS}

All the 55 students were exposed to the same faculty for lectures and CBL and took identical pre-and post-tests. Hence, the consequences, if any, of confounding variables would cancel out.

\section{Distribution of correct responses}

The mean score was $5.36 \pm 0.97$ (95\% CI: 5.11 - 5.62) in the pre-test and $6.49 \pm 1.14(95 \% \mathrm{CI}: 6.19-6.79)$ in the post-test.

Significant differences were observed between the correct responses obtained during the pre- and post-test for question No. 4 ( $\mathrm{p}=0.004)$ and question No. 9 ( $\mathrm{p}=0.049)$.

The difference in pre-test (49.09\% correct responses) and post-test $(67.27 \%$ correct responses) for question No. 1 did not reach a level of statistical significance $(\mathrm{p}=0.053)$.

The correct responses for the remaining questions during the post-test were higher than that for the pre-test but were not statistically significant (Table 1). 


\section{Question-wise scores in pre- and post-tests}

Though there was substantial improvement in the mean scores in all the nine questions between the pre-and posttests, only the differences between the mean correct responses obtained during the pre- and post-test for question Nos. $4(\mathrm{p}=0.0026)$ and $9(\mathrm{p}=0.0488)$ were statistically significant (Table 2). For question No. 4, students who gave correct answers in the pre- and posttests comprised $36.36 \%$ and $63.64 \%$, respectively and the mean score increased from $0.36 \pm 0.49$ (95\% CI: 0.24 $0.49)$ in the pre-test to $0.64 \pm 0.49$ (95\% CI: $0.51-0.76)$ in the post-test. Likewise, for question No. 9, students who answered correctly in the pre- and post-tests comprised $52.73 \%$ and $70.91 \%$, respectively and the mean score increased from $0.53 \pm 0.50$ (95\% CI: 0.39 $0.66)$ in the pre-test to $0.71 \pm 0.46$ (95\% CI: $0.59-0.83)$ in the post-test.
Table 1: Distribution of correct responses in pre- and post-tests.

\begin{tabular}{|lllll|}
$\begin{array}{l}\text { Pre-test } \\
(n=55)\end{array}$ & $\begin{array}{l}\text { Post-test } \\
(\mathbf{n = 5 5})\end{array}$ & $\begin{array}{l}\text { Chi }^{2} \\
\text { value \# }\end{array}$ & $\begin{array}{l}\text { p value } \\
\text { Odds }\end{array}$ & $\begin{array}{l}\text { Ratio } \\
\text { Ra }\end{array}$ \\
\hline $36(65.45)$ & $40(67.27)$ & 3.736 & 0.053 & 0.469 \\
\hline $39(70.91)$ & $40(72.73)$ & 0.681 & 0.409 & 0.71 \\
\hline $20(36.36)$ & $35(63.64)$ & 8.182 & $0.004 *$ & 0.326 \\
\hline $31(56.36)$ & $40(72.73)$ & 3.218 & 0.073 & 0.484 \\
\hline $37(67.27)$ & $41(74.55)$ & 0.705 & 0.401 & 0.702 \\
\hline $33(60.00)$ & $42(76.36)$ & 3.394 & 0.065 & 0.464 \\
\hline $38(69.09)$ & $43(78.18)$ & 1.171 & 0.279 & 0.624 \\
\hline $29(52.73)$ & $39(70.91)$ & 3.851 & $0.049 *$ & 0.457 \\
\hline
\end{tabular}

Figures in parentheses indicate percentages

\#Karl Pearson's Chi square test with Mantel-Haenszel correction, where required. $*$ Statistically significant

Table 2: Mean correct responses in pre- and post-tests.

\begin{tabular}{|c|c|c|c|c|c|c|c|}
\hline \multicolumn{3}{|c|}{ Pre-test $(\mathrm{n}=55)$} & \multicolumn{3}{|c|}{ Post-test ( $(\mathrm{n}=\mathbf{5 5})$} & \multirow{2}{*}{$\mathrm{Z}$ value } & \multirow{2}{*}{ p value } \\
\hline Mean & SD & CI & Mean & SD & CI & & \\
\hline 0.49 & 0.50 & $0.36-0.62$ & 0.67 & 0.47 & $0.55-0.79$ & 1.945 & 0.0512 \\
\hline 0.65 & 0.48 & $0.52-0.78$ & 0.73 & 0.45 & $0.61-0.85$ & 0.902 & 0.3682 \\
\hline 0.71 & 0.46 & $0.59-0.83$ & 0.73 & 0.45 & $0.61-0.85$ & 0.230 & 0.818 \\
\hline 0.36 & 0.49 & $0.23-0.49$ & 0.64 & 0.49 & $0.51-0.77$ & 2.997 & $0.0026 *$ \\
\hline 0.56 & 0.50 & $0.43-0.69$ & 0.73 & 0.45 & $0.61-0.85$ & 1.874 & 0.0614 \\
\hline 0.67 & 0.47 & $0.55-0.79$ & 0.75 & 0.44 & $0.83-0.87$ & 0.922 & 0.3576 \\
\hline 0.60 & 0.49 & $0.47-0.73$ & 0.76 & 0.43 & $0.65-0.87$ & 1.820 & 0.0688 \\
\hline 0.69 & 0.47 & $0.57-0.81$ & 0.78 & 0.42 & $0.67-0.89$ & 1.059 & 0.2892 \\
\hline 0.53 & 0.50 & $0.40-0.66$ & 0.71 & 0.46 & $0.59-0.83$ & 1.965 & $0.0488 *$ \\
\hline
\end{tabular}

$\mathrm{Z}=$ Standard error of difference between means; $\mathrm{SD}=$ Standard deviation; $\mathrm{CI}=$ Confidence interval at $95 \%$ confidence limits. $*$ Statistically significant.

Table 3: Gender differences in question-wise mean correct responses in the pre-test.

\begin{tabular}{|lllllllll|}
\hline Females $(\mathrm{n}=30)$ & \multicolumn{3}{c}{ Males $(\mathrm{n}=25)$} & & \multicolumn{2}{c}{ Z value } & p value \\
\hline Mean & SD & CI & Mean & SD & CI & $0.041 *$ \\
\hline 0.37 & 0.49 & $0.19-0.55$ & 0.64 & 0.49 & $0.45-0.83$ & 2.035 & 0.193 \\
\hline 0.73 & 0.45 & $0.57-0.89$ & 0.56 & 0.51 & $0.36-0.76$ & 1.3 & 0.303 \\
\hline 0.77 & 0.43 & $0.62-0.92$ & 0.64 & 0.49 & $0.45-0.83$ & 1.03 & 0.246 \\
\hline 0.43 & 0.50 & $0.25-0.61$ & 0.28 & 0.46 & $0.10-0.46$ & 1.157 & 0.610 \\
\hline 0.53 & 0.51 & $0.35-0.71$ & 0.60 & 0.50 & $0.40-0.80$ & 0.512 & 0.103 \\
\hline 0.77 & 0.43 & $0.62-0.92$ & 0.56 & 0.51 & $0.36-0.76$ & 1.632 & 0.099 \\
\hline 0.70 & 0.47 & $0.53-0.87$ & 0.48 & 0.51 & $0.28-0.68$ & 1.65 & 0.704 & 0.484 \\
\hline 0.73 & 0.45 & $0.57-0.89$ & 0.64 & 0.49 & $0.45-0.83$ & 0.704 \\
\hline 0.50 & 0.51 & $0.32-0.68$ & 0.56 & 0.51 & $0.36-0.76$ & 0.434 & 0.667 \\
\hline
\end{tabular}

$\mathrm{Z}=$ Standard error of difference between means; $\mathrm{SD}=$ Standard deviation; $\mathrm{CI}=$ Confidence interval at $95 \%$ confidence limits. $*$

Statistically significant

\section{Gender differences}

In the pre-test, the mean score for female students was $5.53 \pm 0.94$ (95\% CI: 5.20 - 5.87), while that for their male counterparts was $4.96 \pm 1.06$ (95\% CI: $4.54-5.38)$. In the post-test, the mean score for female students increased to $6.70 \pm 1.06$ (95\% CI: 6.32 - 7.08), while that for the male students increased to $6.24 \pm 1.20$ (95\% CI: 5.77 - 6.21). For both male and female students, the first quartile and median were identical (5) in the pre-test and were merged in the box plot (Figure 1), implying that $50 \%$ of the 
students gave correct responses to 5 out of 9 questions in the pre-test. Likewise, the third quartile was also identical (6) for both genders. Female students had obtained a higher minimum score (4) in the pre-test as compared to the males (3).

In the post-test, the minimum score was 4 for both sexes. Both male and female students showed identical improvement in scores in the other parameters (first quartile, median merged with third quartile and the maximum) in the post-test. The merging of the third quartile (7) and the median (7) for both male and female students in the post-test denotes that $75 \%$ of the students gave correct responses to 7 out of 9 questions in the posttest.

Significant gender difference $(\mathrm{p}=0.041)$ was observed for question No. 1 in the pre-test. (Table 3) In the post-test, gender differences were significant for question Nos. 7 $(\mathrm{p}=0.048)$ and question No. $8(\mathrm{p}=0.021)($ Table 4$)$.

Table 4: Gender differences in question-wise mean correct responses in the post-test.

\begin{tabular}{|c|c|c|c|c|c|c|c|}
\hline \multicolumn{3}{|c|}{ Females $(\mathrm{n}=\mathbf{3 0})$} & \multicolumn{3}{|c|}{ Males $(\mathrm{n}=\mathbf{2 5})$} & \multirow{2}{*}{$\mathrm{Z}$ value } & \multirow{2}{*}{ p value } \\
\hline Mean & SD & CI & Mean & SD & CI & & \\
\hline 0.67 & 0.48 & $0.50-0.84$ & 0.68 & 0.48 & $0.49-0.87$ & 0.077 & 0.936 \\
\hline 0.73 & 0.45 & $0.57-0.89$ & 0.72 & 0.46 & $0.54-0.90$ & 0.081 & 0.936 \\
\hline 0.73 & 0.45 & $0.57-0.89$ & 0.72 & 0.46 & $0.54-0.90$ & 0.081 & 0.936 \\
\hline 0.60 & 0.50 & $0.42-0.78$ & 0.68 & 0.48 & $0.49-0.87$ & 0.604 & 0.548 \\
\hline 0.70 & 0.47 & $0.53-0.87$ & 0.76 & 0.44 & $0.59-0.93$ & 0.488 & 0.624 \\
\hline 0.83 & 0.38 & $0.69-0.97$ & 0.64 & 0.49 & $0.45-0.83$ & 1.582 & 0.114 \\
\hline 0.87 & 0.35 & $0.74-1.00$ & 0.64 & 0.49 & $0.45-0.83$ & 1.966 & $0.048 *$ \\
\hline 0.90 & 0.31 & $0.79-1.01$ & 0.64 & 0.49 & $0.45-0.83$ & 2.297 & $0.021 *$ \\
\hline 0.67 & 0.48 & $0.50-0.84$ & 0.76 & 0.44 & $0.59-0.93$ & 0.725 & 0.465 \\
\hline
\end{tabular}

$\mathrm{Z}=$ Standard error of difference between means; $\mathrm{SD}=$ Standard deviation; $\mathrm{CI}=$ Confidence interval at $95 \%$ confidence limits. $*$ Statistically significant

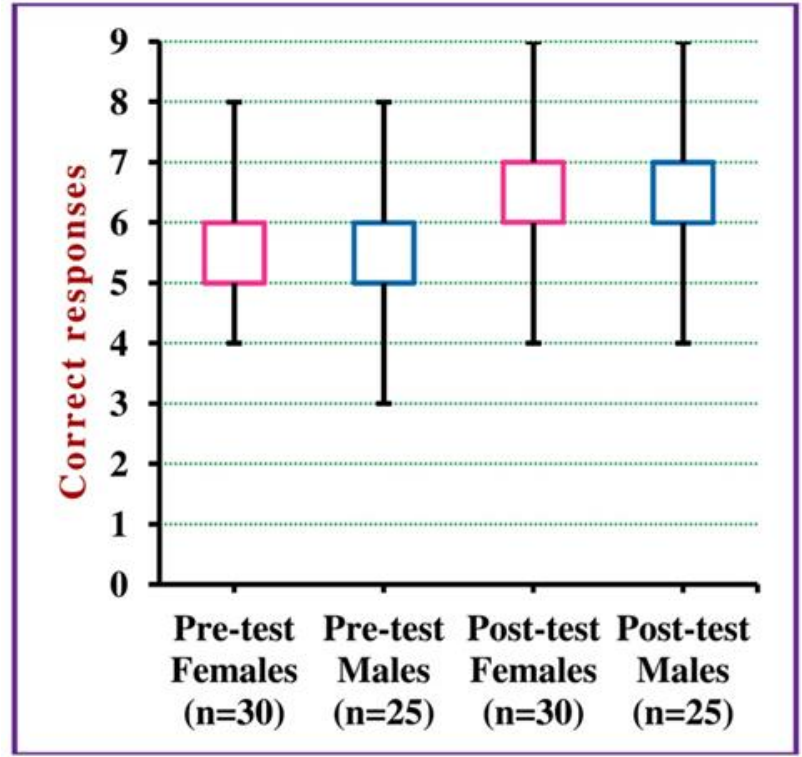

Figure 1: Distribution of correct responses in pre- and post-tests.

\section{DISCUSSION}

The purpose of education is to enable students to apply their knowledge across a variety of situations, domains, and contexts. The formation of several interconnected mental models enables students to acquire a broad outlook and to utilise their knowledge in practical settings. ${ }^{15}$ It has been reported that physiology of pregnancy and STIs/HIV was given higher coverage in contrast to contraceptive methods and elective abortion procedures in the United States and Canada. ${ }^{16}$

In the present study, significant differences were observed between correct responses in the pre- and posttests for question Nos. 4 and 9. Both these questions pertained to contraception, a topic perceived by students to be of practical importance. Similar results have been obtained by researchers from Kerala and Nairobi, Kenya; while contrasting findings were reported by studies from North-West India and Bangalore. ${ }^{17-20}$ Activation of the learner's prior knowledge is a pre-requisite for knowledge transfer. ${ }^{21}$ Reflection and self-learning during CBL discussions enable transfer of past knowledge so that students become adept in generalising their knowledge to a broad range of contexts and to apply it in practical settings. ${ }^{22}$ CBL transforms teachers into facilitators who permit students to explore and scrutinise real or hypothetical situations and while debating alternative solutions, the students understand complicated issues and analyse them more effectively. ${ }^{23}$ Moreover, CBL generates considerable enhancement in student learning and retention, as compared to the traditional lecture format. ${ }^{7,8,10}$ Traditional lectures impart theoretical knowledge that is restricted to the cognitive domain. Minor differences in scores have been reported when the post-tests were conducted one and six months after 
CBL. ${ }^{11}$ Thus, administering a post-test immediately after an educational intervention seems logical and convenient.

Furthermore, during CBL, students discuss and give valid justifications for various probable diagnoses and investigations. During CBL, the student's discussions may help them relate to patients in underprivileged settings and thus their application of knowledge would also stretch to the affective domain. ${ }^{11}$ Researchers have used a variety of teaching-learning strategies, such as, video clippings, role plays and case scenarios, to increase the attention span of the students during learning sessions. $^{24-26}$

Limitations of the present study were that it was conducted on only one batch of 55 first-year medical students using case scenarios pertaining to reproductive physiology. The students could not be exposed to real-life patients due to time constraints of the first year MBBS course. For generalising the results, a larger study using case scenarios linked to the entire Physiology curriculum would be needed.

\section{CONCLUSION}

The participating first-year medical students had adequate basic knowledge of reproductive physiology. Statistically significant gender differences in correct responses were obtained in a small number of questions only and were not significant in most questions. Use of case scenarios enhanced cognitive domain scores.

\section{Funding: No funding sources}

Conflict of interest: None declared

Ethical approval: The study was approved by the Institutional Ethics Committee

\section{REFERENCES}

1. Medical Council of India. Regulations on Graduate Medical Education, 1997. Amended up to 10th March 2017. 2017:23. Available at: http://www.mciindia.org/Rules-and

Regulation/GME_REGULATIONS.pdf Accessed 26 Mar 2017.

2. Kireeti AS, Reddy DS. Case based learning (CBL), a better option to traditional teaching for undergraduate students in curriculum of Paediatr. Asian J Biomed Pharm Sci. 2015;5(45):39-41.

3. Norman GR, Schmidt HG. Effectiveness of problembased learning curricula: theory, practice and paper darts. Med Educ. 2000;34(9):729-738.

4. Vora MB, Shah CJ. Case based learning in pharmacology: moving from teaching to learning. Int J Appl Basic Med Res. 2015;5(1):21-3.

5. Joshi KB, Nilawar AN, Thorat AP. Effect of case based learning in understanding clinical biochemistry. Int J Biomed Adv Res. 2014;5(10): 516-8.
6. Majeed F. Effectiveness of case-based teaching of physiology for nursing students. J Taibah Univ Med Sci. 2014;9(4):289-92.

7. Subramanian A, Timberlake M, Mittakanti H, Lara M, Brandt ML. Novel educational approach for medical students: improved retention rates using interactive medical software compared with traditional lecture-based format. J Sur Educ. 2012;69(2):253-256.

8. Hansen WF, Ferguson KJ, Sipe CS, Sorosky J. Attitudes of faculty and students toward case-based learning in the third-year obstetrics and gynecology clerkship. Am J Obstet Gynecol. 2005;192(2):644-7.

9. Nanda B, Manjunatha S. Indian medical students' perspectives on problem-based learning experiences in the undergraduate curriculum: one size does not fit all. J Educ Eval Health Prof. 2013;10:11.

10. Kassebaum D, Averbach R, Fryer G. Student preference for a case-based vs. lecture instructional format. J Dent Educ. 1991;55(12):781-784.

11. Kartikeyan S, Malgaonkar AA. Retention of casebased learning on infectious diseases by third-year medical students. Int J Res Med Sci. 2016;4(1):2727.

12. Bledsoe KE. Managing problem-based learning in large lecture sections. Biosci Edu. 2011;18(1):1-1.

13. Sathishkumar S, Thomas N, Tharion E, Neelakantan $\mathrm{N}$, Vyas R. Attitude of medical students towards early clinical exposure in learning endocrine physiology. BMC Med Educ. 2007;7:30.

14. Dunaway GA, Faingold CL. Development and implementation of a multidisciplinary sophomore medical curriculum: Integration of pharmacology with basic and clinical sciences. Pharmacologist. 2001;43:83-90.

15. Michael J. In pursuit of meaningful learning. Adv Physiol Educ. 2001;25(3):145-58.

16. Steinauer J, LaRochelle F, Rowh M, Backus L, Sandahl Y, Foster A. First impressions: what are preclinical medical students in the US and Canada learning about sexual and reproductive health? Contraception. 2009;80(1):74-80.

17. Iliyas MC. A cross sectional study on awareness about emergency contraception among medical students in Kannur, Kerala, India. Int J Comm Med Pub Health 2016;3(11):3216-9.

18. Gichangi PB, Karanka JG, Kigondu CS, Konck K, Temmerman M. Knowledge, attitudes, and practices regarding emergency contraception among nurses and nursing students in two hospitals in Nairobi, Kenya. Contraception 1999;59(4):253-6.

19. Gupta RK, Raina SK, Verma AK, Shora T. Emergency contraception: Knowledge and attitude toward its use among medical students of a medical college in North-West India. J Pharm Bioallied Sci 2016;8(3):235-9.

20. Reddy NR, Kishore SG, Basha SR. Knowledge on Emergency Contraception among medical students in Bangalore, Karnataka. JEMDS. 2014;3(2):369-73. 
21. Bransford JD, Brown AL, Cocking RR (Eds.) How people learn-mind, brain, experience and school. Washington DC: National Academy Press. 2000:218. Available at: https://www.nap.edu/Accessed: $27 \mathrm{Mar}$ 2017.

22. Sawyer RK. Introduction: The New Science of Learning. In: R. K. Sawyer (Ed.). The Cambridge Handbook of the Learning Sciences. New York: Cambridge University Press; 2006:1-16.

23. Lombardi MM. Authentic learning for the 21st century: An overview. Educause learning initiative. Oblinger DG (Ed.). ELI Paper 1: 2007. Available at: https://net.educause.edu/ir/library/pdf/ELI3009.pdf Accessed: 26 Mar 2017.

24. Manivasakan J, Arunasolamme B. Contraception module: innovative strategies to improve students learning. Int J Reprod Contracept Obstet Gynecol. 2015;4(5):1489-93.
25. Ghayur S, Rafi S, Khan AH, Ahmad RN, Iqbal M. Delivering endocrinology and reproduction in an integrated modular curriculum. J Pak Med Assoc. 2012;62(9):937-41.

26. Goodman BE, Koster KL, Redinius PL. Comparing biology majors from large lecture classes with TAfacilitated laboratories to those from small lecture classes with faculty-facilitated laboratories. Adv Physiol Educ. 2005;29(2):112-7.

Cite this article as: Bhattacharya SN, Malgaonkar AA, Kartikeyan S. Effect of case-based learning in reproductive physiology on cognitive domain scores of first-year medical students in Western India. Int J Reprod Contracept Obstet Gynecol 2017;6:2559-64. 